\title{
Airport Congestion Pricing When Airlines Price Discriminate
}

\section{Achim I. Czerny}

WHU - Otto Beisheim

School of Management achim.czerny@whu.edu
Anming Zhang

University of

British Columbia

anming.zhang@sauder.ubc.ca

WHU - Working Paper

Series in Economics

WP 12/02 


\title{
Airport Congestion Pricing When Airlines Price Discriminate
}

\author{
Achim I. Czerny* \\ WHU - Otto Beisheim School of Management \\ achim.czerny@whu.edu \\ Anming Zhang \\ University of British Columbia \\ anming.zhang@sauder.ubc.ca \\ January 17, 2012
}

\begin{abstract}
This paper develops a tractable model of third-degree price discrimination in airline markets that features two types of passengers with different time valuations, carriers in Cournot competition and a congested infrastructure. We find that price discrimination always leads to a loss of social welfare when, in the first stage, the congestion charge is chosen to maximize welfare by incorporating carriers' behavior in the second stage. We also show that the welfare loss can be small if, in the process of choosing the optimal airport charges, carriers were treated as atomistic.
\end{abstract}

JEL Classification: D43, D62, H23, L13, L93, R41, R48.

Keywords: Price discrimination, infrastructure, congestion, Cournot competition, airlines.

${ }^{*}$ We thank Kurt van Dender, Markus Reisinger, Yimin Zhang and the participants of the GARS Workshop in Hamburg 2011 and the Kuhmo-Nectar Conference 2011 for helpful comments and suggestions. 


\section{Introduction}

This paper investigates the effect of third-degree price discrimination on social welfare (consumer and producer surplus), focusing on airline markets. Airlines are a frequently used example for markets where price discrimination is prevalent (e.g. Borenstein 1985, Dana 1999/1999a and Cowan 2007). Special elements of airline markets, besides price discrimination, are that they incorporate a vertical structure with a monopolistic, congested infrastructure - namely, airport - and oligopolistic carriers. The main objective of this paper is to demonstrate how third-degree price discrimination affects social welfare in airline markets and how fare structures change the welfare-optimal airport congestion charge relative to a scenario with uniform fares.

The effect of monopolistic price discrimination on welfare is well understood for scenarios with independent demands and without externalities. Here, price discrimination can have two effects: 1) it affects welfare because, with price discrimination, marginal utilities are no longer the same between consumers; and 2) it changes outputs. This second effect can outweigh the first negative welfare effect if the output effect of price discrimination is positive in sign. Varian (1985) showed that price discrimination reduces welfare when output is not increasing relative to the output under uniform pricing for both the independent demands and interdependent demands. The output effects of price discrimination depend on the curvature of demand functions, which have been analyzed by Robinson (1933), Schmalensee (1981) and Holmes (1989). More recently, by assuming independent demands, Aguiree, Cowan and Vickers (2010) derived conditions for the curvature of demand functions that are informative with respect to the welfare effect of price discrimination.

Demands are, however, interdependent in airline markets. To see this, consider two groups of passengers, business and leisure passengers. The distinction between business and leisure passengers is useful for three reasons: 1) business passengers often exhibit a lower price elasticity of demand than leisure passengers; 2) business passengers have a greater value of time than leisure passengers (e.g. Morrison 1987, Morrison and Winston 1989, US Department of Transportation 1997, and Pels et al. 2003); and 3) business passengers book their flights relatively late so that airlines can price discriminate between business and leisure passengers by advanced-purchase rebates 
(e.g. Stavins 2001 and Hazledine 2006). ${ }^{1}$ Following Robinson's (1933) diction, the business-passenger market is called the "strong" market and the leisure-passenger market the "weak" market. Fares in the strong market are denoted by $p_{s}$ and fares in the weak market by $p_{w}$, with $p_{s} \geq p_{w}$. Since airport capacity is limited, passengers buy a ticket and also experience delays at the airport (e.g. Daniel 1995, Brueckner 2002, Mayer and Sinai 2003, Morrison and Winston 2007). The "full price" of traveling is, therefore, determined by the sum of the fare and the (per passenger) congestion costs. These congestion costs are determined by the product of the per-passenger delay (which is assumed to be the same for all passengers), denoted by $C \geq 0$, and the values of time. Denoting the time values by $v_{s}$ and $v_{w}$ for the two passenger types, the full prices can then be written as $p_{s}+v_{s} C$ and $p_{w}+v_{w} C$, and in the demand equilibrium the marginal utility of traveling is equal to the full price for every passenger. Assuming a positive relationship between delay $C$ and passenger numbers, and a negative relationship between marginal utilities and passenger numbers, then an increase in the number of leisure passengers will increase the full price of business passengers, and thus reduce their travel demand, when fares are given. Similarly, an increased number of business passengers reduces the leisure passengers' travel demand, which illustrates the demand interdependencies.

A further consequence arising from the difference in time valuations is that marginal utilities of passengers differ in the welfare maximum. Czerny and Zhang (2011) showed, with two passenger types of different time valuations, that a uniform fare leads to the first-best solution; consequently, price discrimination with respect to full prices is necessary to reach the firstbest outcome. The economic intuition for this result is that a passenger's congestion effect on all the other passengers is independent of her own time valuation; thus, the congestion externality to be internalized by fares to passengers is independent of the passenger type. By contrast, marginal costs do depend on the passenger's time valuation and they are different for business and leisure passengers in the welfare maximum for this reason, which is also true for marginal utilities in the welfare maximum.

This paper explores airline price discrimination by incorporating congestion effects and passenger types when all markets are served. A twostage game is considered, where the airport congestion charge is chosen to

\footnotetext{
${ }^{1}$ Nocke et al. (2011) analyze advance-purchase discounts in the digital economy.
} 
maximize social welfare in the first stage. In the second stage, symmetric carriers engage in Cournot competition. To analyze the effect of price discrimination, it is assumed that carriers simultaneously and independently choose passenger numbers in the strong and the weak market subject to a price-difference constraint (price-difference constraints have also been used by, e.g., Schmalensee 1981, Holmes 1989 and Aguiree, Cowan and Vickers 2010). In this scenario, a price difference of zero replicates the carrier equilibrium under uniform pricing. This describes a situation where each carrier chooses its total number of passengers but where the share of business and leisure passengers is determined by the uniform airfare. The non-binding price-difference constraint replicates the laissez-faire result with price discrimination. This describes a situation where it is assumed that each carrier can determine its number of business passengers separately from its number of leisure passengers as it would be the case when the carriers would be active in two separate markets. Business and leisure passenger markets are not fully separated under price discrimination, however, because congestion links the two markets.

A straightforward but important result of our analysis is that, in the subgame-perfect equilibrium, price discrimination always leads to a loss of social welfare relative to the absence of price discrimination. This is because, by the "right" choice of the congestion charge, the first-best solution can always be reached under uniform fares and only under uniform fares. It is also shown that the second-best discriminating fare in the strong market always exceeds the first-best uniform fare, while the second-best discriminating fare in the weak market is always lower than the first-best uniform fare in the subgame-perfect equilibrium. This complements the findings of Holmes (1989), who considered a differentiated Bertrand oligopoly and also found that price discrimination leads to a higher price in the strong market and a lower price in the weak market. The effect of price discrimination on welfare and fare structures is more difficult to predict when the congestion charge is considered as given. In this scenario, parameter constellations exist where welfare is increased by price discrimination although output is reduced relative to the absence of price discrimination. Moreover, parameter constellations exist where price discrimination increases fares in both the 
strong and weak markets, which stands in contrast to the results derived by Holmes. ${ }^{2}$

With respect to the congestion charge, it is shown that the welfareoptimal congestion charge can be higher than what would be expected when all passengers would have the same time valuations. Furthermore, the effect of differences in time valuation on the congestion charge is independent of whether carriers engage in price discrimination or charge uniform fares. This shows that the relationship between time valuations and infrastructure congestion charges found by Czerny and Zhang (2011) - who concentrated on uniform fares - is robust with respect to the carriers' pricing behavior.

The paper is organized as follows. Section 2 presents the model specifications based on general functional forms. Section 3 analyzes the equilibrium fares and passenger numbers when the infrastructure charge is given. Specific functional forms and numerical instances are further used to show that price discrimination can reduce the total number of passengers and improve social welfare at the same time. Section 4 demonstrates that the first-best outcome can only be reached under uniform pricing. This section further elaborates on the welfare-optimal congestion charge and shows that, in the subgame-perfect equilibrium, fares in the strong market are increased by price discrimination, while fares in the weak market are reduced. Section 5 contains concluding remarks.

\section{The Model}

Consider an origin-destination air travel market. Passengers are partitioned in two groups: the first group is called the strong market and the second group the weak market. Let $q_{s}$ denote the passenger number in the strong market and $q_{w}$ the passenger number in the weak market. Setting aside congestion, passenger utilities (gross benefits from travel) in the strong market are $B_{s}\left(q_{s}\right)$ and passenger utilities in the weak market $B_{w}\left(q_{w}\right)$. Utility functions are three times continuously differentiable with $B_{x}^{\prime}>0$ and $B_{x}^{\prime \prime}<0$ for all $x \in\{s, w\}$.

There is a single, public infrastructure-provider (airport) in the upstream market with limited capacity supply. A consequence of the limited capacity is that passengers incur congestion delays at the airport. The average delays

\footnotetext{
${ }^{2}$ Strict application of Robinson's (1933) diction would then mean that both markets are strong and a weak market does not exist.
} 
depend on $q$, the total number of passengers $\left(q=q_{s}+q_{w}\right)$, and are denoted as $C(q)$ with $C^{\prime}>0$ and $C^{\prime \prime} \geq 0$. Average delays $C$ are, thus, increasing and convex in the number of total passengers, and are constant over all passengers. The values of time depend, on the other hand, on passenger types: Denoting the value of time in the strong (weak, respectively) market by $v_{s}\left(v_{w}\right.$, respectively), we have $v_{s} \geq v_{w}(>0)$.

Customers are served by $n$ symmetric carriers in the downstream market that provide homogenous services. Let $q_{s i}\left(q_{w i}\right)$ denote the number of passengers in the strong (weak) market who are carried by carrier $i$, with $i=1,2, \ldots, n$ and $q_{x}=\sum_{i=1}^{n} q_{x i}$ for $x \in\{s, w\}$. Carriers charge a price denoted by $p_{s}$ to passengers in the strong market and a price $p_{w}$ to passengers in the weak market (think of advanced-purchase rebates for leisure passengers). Passengers consider average delays as given; thus, there is a "full price" of traveling, denoted $\eta_{x}$, that is composed of the fare and delay costs: $\eta_{x}=p_{x}+v_{x} C$, for $x \in\{s, w\}$. Assuming $B_{x}^{\prime}=\eta_{x}$ in the demand equilibrium and rearranging yields inverse demands

$$
P_{x}=B_{x}^{\prime}-v_{x} C
$$

for $x \in\{s, w\}$. Since $\partial P_{x} / \partial q_{y}=-v_{x} C^{\prime}<0$ for $x, y \in\{s, w\}$, the inverse demands in (1) are interdependent. (Here, and below, if the indices $x$ and $y$ appear in the same expression, then it is to be understood that $y \neq x$.)

Infrastructure behavior and carrier behavior are modeled as a two-stage game. In the first stage, the infrastructure provider (airport) chooses a perpassenger fee $\tau$ to maximize social welfare. As all the infrastructure-related costs are to be abstracted away from our analysis, $\tau$ is charged to carriers to internalize congestion externality, and thus may be referred to as the congestion charge. ${ }^{3}$ In the second stage, carriers choose quantities $q_{s i}$ and $q_{w i}$ simultaneously and independently to maximize profit; that is, carriers are in Cournot competition. ${ }^{4}$ Carriers' operating costs are normalized to zero and so the congestion charge $\tau$ is the only cost for carriers. The subgame perfect equilibrium of the game will be examined.

\footnotetext{
${ }^{3}$ While in many real cases public subsidies are not available for infrastructure providers because of limited public funds, negative values of $\tau$ may still be considered in our context so as to simplify some of the analysis.

${ }^{4}$ Empirical studies by, e.g., Brander and Zhang (1990) and Oum, Zhang and Zhang (1993) provide support for the assumption that Cournot competition prevails in the airline market.
} 
To compare outcomes under uniform pricing and price discrimination, a "price-difference constraint" is imposed. This constraint implies that passengers in the strong market are charged with a premium determined by $\phi \geq 0$ relative to the fare charged to passengers in the weak market $\left(p_{s}=p_{w}+\phi\right)$. In this scenario, uniform pricing is considered when $\phi=0$, while (strict) price discrimination occurs when $\phi>0$. Moreover, if $\phi>0$ and the pricedifference constraint is non-binding, this replicates the laissez-faire outcome. Observe that $\phi$ determines the differential between fares in the strong and weak markets (rather than the level of fares).

\section{Carrier Price Discrimination}

\subsection{General functional forms}

This section examines the second-stage subgame. Carrier $i$ 's profit can be written, from (1), as

$$
\Pi^{i}=\sum_{x} q_{x i}\left[P_{x}\left(q_{s}, q_{w}\right)-\tau\right]
$$

for $i=1, \ldots, n$. In stage 2 , carriers choose quantities $q_{s i}$ and $q_{w i}$ to maximize their profits $\Pi^{i}$ under the price-difference constraint $g=0$ for $i=1, \ldots, n$, with $g=\phi-\left(P_{s}-P_{w}\right)$ and $\phi \geq 0$. The associated Lagrangian can be written as

$$
\mathscr{L}^{i}=\Pi^{i}+\lambda^{i} g
$$

for $i=1, \ldots, n$, where $\lambda^{i}$ are Lagrange multipliers. Assume that $\lambda^{i} \geq 0$, which implies that carriers want to charge passengers in the strong market with a higher fare than passengers in the weak market.

To save notation, subscripts $x i$ indicate, in the remainder of the paper, partial derivatives with respect to $q_{x i}$ for $x \in\{s, w\}$ (e.g. $\Pi_{x i}^{i} \equiv \partial \Pi^{i} / \partial q_{x i}$ and $\left.\Pi_{x i y i}^{i} \equiv \partial^{2} \Pi^{i} / \partial q_{x i} \partial q_{y i}\right)$. Assume that the Cournot-Nash equilbrium quantities are determined by the carriers' first-order conditions

$$
\Pi_{x i}^{i}+\lambda^{i} g_{x i}=0
$$

with

$$
\Pi_{x i}^{i}=\left(B_{x}^{\prime}-v_{x} C-\tau\right)+\left(B_{x}^{\prime \prime}-v_{x} C^{\prime}\right) q_{x i}-q_{y i} v_{y} C^{\prime}
$$




$$
g_{s i}=-B_{s}^{\prime \prime}+\left(v_{s}-v_{w}\right) C^{\prime} \quad \text { and } \quad g_{w i}=B_{w}^{\prime \prime}+\left(v_{s}-v_{w}\right) C^{\prime}
$$

for $i=1, \ldots, n$ and $x, y \in\{s, w\}$. The first equation in (6) is positive in sign, while the second equation is ambiguous in sign when $v_{s}>v_{w}$. To ensure the existence of solutions for each carrier's choice of passenger numbers, assume that the second-order conditions are satisfied (i.e., the bordered Hessians are negative definit), which holds true when

$$
\operatorname{det}\left[\begin{array}{ccc}
\mathscr{L}_{\text {sisi }}^{i} & \mathscr{L}_{\text {siwi }}^{i} & g_{s i} \\
\mathscr{L}_{\text {siwi }}^{i} & \mathscr{L}_{\text {wiwi }}^{i} & g_{w i} \\
g_{s i} & g_{w i} & 0
\end{array}\right]>0
$$

is satisfied for $i=1, \ldots, n$ (e.g. Gravelle and Rees 2004).

Equilibrium outcomes are obtained by simultaneously solving the firstorder conditions in (4) for $i=1, \ldots, n$. Since $g_{x i}=g_{x j}$ (here, and below, if the indices $i$ and $j$ appear in the same expression, then it is to be understood that $j \neq i$ ), the stability condition for the Cournot equilibrium is satisfied when

$$
\Xi_{i}=\operatorname{det}\left[\begin{array}{ccc}
\mathscr{L}_{\text {sisi }}^{i}+(n-1) \mathscr{L}_{\text {sisj }}^{i} & \mathscr{L}_{\text {siwi }}^{i}+(n-1) \mathscr{L}_{\text {siwj }}^{i} & g_{s i} \\
\mathscr{L}_{w i s i}^{i}+(n-1) \mathscr{L}_{\text {wisj }}^{i} & \mathscr{L}_{\text {wiwi }}^{i}+(n-1) \mathscr{L}_{w i w j}^{i} & g_{w i} \\
n g_{s i} & n g_{w i} & 0
\end{array}\right]>0
$$

for $i=1, \ldots, n$ in equilibrium (Zhang and Zhang 1996), which is assumed to hold. The comparative-static results of passenger numbers, full prices and prices with respect to the infrastructure charge are given in Lemma 1:

Lemma 1 An increase of the congestion charge has the following effects: (i) It can increase or reduce the number of passengers in the strong market only if $v_{s}>v_{w}$, while it always reduces the number of passengers in the weak market and the total number of passengers (sum of passengers in the weak and the strong market). (ii) It increases passenger fares in both the weak and strong markets.

Proof See Appendix A.

The implications of this lemma for the relationship between the congestion charge and the full prices, $\eta_{x}$, are straightforward. 
The comparative-static results stated in Lemma 1 are independent of whether the laissez-faire scenario (price discrimination) or uniform pricing is considered. ${ }^{5}$ They do depend on the difference in time valuation, however. More specifically, a nonnegative relationship between congestion charge $\tau$ and passenger numbers in the strong market can occur only if passengers in the strong market exhibit a greater value of time than passengers in the weak market (i.e., when $v_{s}>v_{w}$ ). This is because an increase in $\tau$ always reduces the number of passengers in the weak market. A negative relationship between $\eta_{s}$ (full price in the strong market) and $\tau$ can, therefore, exist when passengers in the strong market exhibit a sufficiently high value of time. To be precise, this occurs when $v_{s}>v_{w}-B_{w}^{\prime \prime} / C^{\prime}$ (see Appendix A).

The effects of price discrimination on passenger numbers and fares are given below:

Proposition 1 (i) If the demands are non-linear, the effect of price discrimination on passenger numbers in both the strong and weak markets as well as total number of passengers can be positive or negative in sign. (ii) If the demands are linear and $v_{s}=v_{w}$, price discrimination does not change the total number of passengers relative to uniform pricing, while price discrimination reduces the total number of passengers when $v_{s}>v_{w}$. (iii) If price discrimination reduces the total number of passengers, fares in the strong market are increased by price discrimination relative to the uniform fare.

Proof See Appendix B.

The implications of parts i and ii of Proposition 1 for full prices are again straightforward. Furthermore, these parts extend the results obtained by Robinson (1933) and Cheung and Wang (1997) who found, after abstracting away from externalities, that the equilibrium demand is independent of price discrimination when functions are linear.

Although Proposition 1 is illuminating, the effects of price discrimination on passenger numbers, full prices and fares are still difficult to predict. For example, price discrimination can have a positive or negative effect on fares in both the strong and weak markets at the same time when the demands follow non-linear functional forms. These findings differ from the results obtained by Holmes (1989) who found that, relative to uniform pricing, price

\footnotetext{
${ }^{5}$ In a similar setting, uniform pricing has been analyzed by Czerny and Zhang (2011).
} 
discrimination leads to a higher price in the strong market and a lower price in the weak market. It is, however, difficult to directly compare these sets of results because this paper considers homogeneous products, Cournot competition and externalities, while Holmes concentrates on differentiated products and Bertrand competition and abstracts away from externalities.

\subsection{Specific functional forms}

To illustrate the relationships between fares and passenger numbers under price discrimination and uniform pricing, this part introduces specific functional forms and provides numerical instances. Suppose that there are two carriers $(n=2)$, and passenger benefits are

$$
B_{s}=a q_{s}-\frac{b_{s}}{2} q_{s}^{2} \text { and } B_{w}=q_{w}-\frac{b_{w}}{2} q_{w}^{2}
$$

with $a=b_{s}=2$ and $b_{w} \in\{1 / 10,1\}$. The choke price in the strong market exceeds the choke price in the weak market in this instance. On the other hand, the marginal utility function in the strong market is relatively steep compared to the marginal utility function in the weak market. Assume further that average delays are given by $C=q_{s}+q_{w}$ and that $\tau=1 / 3$ and $v_{w}=1$.

Two scenarios are considered. One scenario concentrates on the outcomes under laissez-faire, where $\phi$ is assumed to be such that it implies $\lambda^{i}=0$ for $i=1, \ldots, n$ in equilibrium. This scenario is indicated by $d$ (for "discrimination"). The second scenario concentrates on uniform pricing $(\phi=0)$ and is indicated by $u$ (for "uniform").

Figure 1 displays equilibrium passenger numbers under laissez-faire and uniform pricing for $b_{w}=1 / 10 .{ }^{6}$ Observe that the effect of price discrimination on the total number of passengers is clear-cut and negative $\left(q_{s}^{d}+q_{w}^{d} \leq\right.$ $\left.q_{s}^{u}+q_{w}^{u}\right)$ because utilities in (9) imply linear demands in the full prices, $\rho_{x}$. By contrast, the effect of price discrimination on passenger numbers in the strong market or the weak market can be positive or negative, depending on the time valuations.

\footnotetext{
${ }^{6}$ All figures are displayed for the relevant ranges of $v_{s}$, where passenger numbers and Lagrange multipliers are nonnegative.
} 


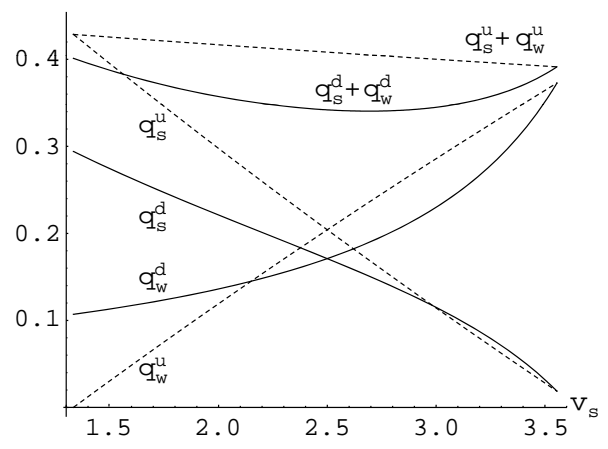

Figure 1: Equilibrium passenger numbers when $\tau$ is given. Parameters: $a=b_{s}=2, b_{w}=1 / 10, v_{w}=1, n=2$ and $\tau=1 / 3$.

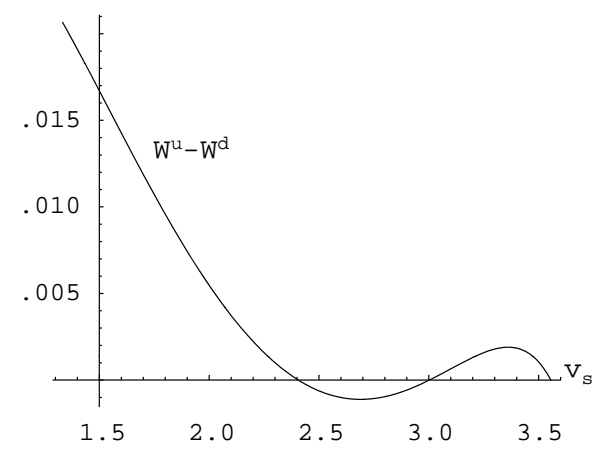

Figure 2: Equilibrium welfare differential when $\tau$ is given. Parameters: $a=b_{s}=2, b_{w}=1 / 10, v_{w}=1, n=2$ and $\tau=1 / 3$.

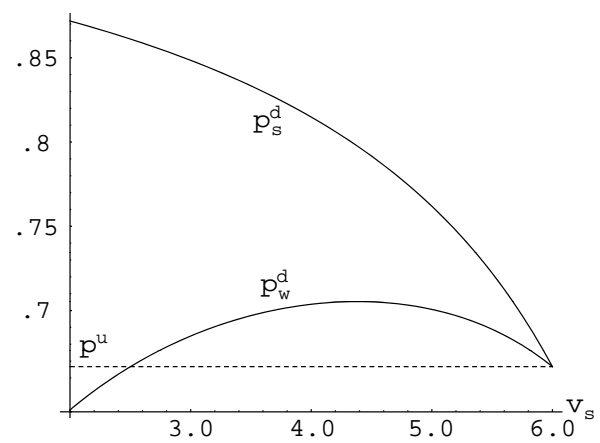

Figure 3: Equilibrium passenger fares when $\tau$ is given. Parameters: $a=b_{s}=2, b_{w}=1, v_{w}=1, n=2$ and $\tau=1 / 3$. 
It is illuminating to consider the welfare effects of price discrimination in this scenario. Social welfare depends on passenger numbers and can be written as

$$
W=\sum_{x}\left(\int_{0}^{q_{x}^{z}} P_{x} d q_{x}-q_{x} v_{x} C\right)
$$

with $z \in\{d, u\}$. Figure 2 displays the welfare under uniform pricing minus welfare under laissez-faire $\left(W^{u}-W^{d}\right)$ implied by the passenger numbers in Figure 1. Observe that welfare under differentiated fares can be higher than welfare under uniform fares. This is because a carrier's choice of passenger numbers imposes congestion effects on its rival carriers. As a consequence, the total number of passengers in equilibrium can be too large from the welfare perspective. Since price discrimination reduces the total number of passengers in the current scenario, this can reduce congestion externalities and lead to higher welfare. The setting considered in this paper, therefore, extends the results derived by Schmalensee (1981) and Varian (1985), who abstracted away from externalities and found that a reduction of the total number of customers always implies welfare losses. For this welfare result (welfare can be higher under price discrimination) to hold, it is crucial that the congestion charge is given - as is to be shown in the following section, this welfare result does not hold in the subgame-perfect equilibrium.

Figure 3 displays equilibrium fares under laissez-faire and uniform pricing for $b_{w}=1$. This figure shows a clear-cut and nonnegative relationship between price discrimination and fares in the strong market (see Proposition 1). The effect of price discrimination on fares in the weak market can, however, be positive or negative, which again depends on time valuations. Thus, price discrimination can increase fares in both the strong and weak markets at the same time. The intuition is that carriers reduce passenger numbers in the weak market in order to reduce delays and charge greater fares in the strong market. This stands in contrast to the results derived by Holmes (1989), who concentrates on differentiated Bertrand oligopoly and abstracts away from externalities, however.

To come up with a nonnegative relationship between the total number of passengers and price discrimination, nonlinear demand functions need to be introduced (see Proposition 1 again). Suppose that the functional form of 


\begin{tabular}{lrrrrrrrr}
\hline & $\tau$ & $q_{s}$ & $q_{w}$ & $q$ & $p_{s}$ & $p_{w}$ & $\eta_{s}$ & $\eta_{w}$ \\
\hline \hline Uniform pricing & 0.100 & 0.628 & 0.028 & 0.657 & 0.413 & 0.413 & 1.005 & 0.971 \\
Laissez-faire & 0.100 & 0.554 & 0.106 & 0.660 & 0.333 & 0.499 & 1.093 & 0.894 \\
\hline
\end{tabular}

Table 1: Equilibrium outcomes when the demand in the strong market is concave and the congestion charge is given. Parameters: $v_{s}=18 / 20, v_{w}=17 / 20, n=3$.

passenger benefits in the weak market remains unchanged, but that passenger benefits in the strong market are determined by

$$
B_{s}=\frac{7}{2} q_{s}-\frac{1}{3} q_{s}^{3}
$$

Suppose further that $v_{s}=18 / 20, v_{w}=17 / 20, n=3$ and $\tau=1 / 10$. This setting implies a strictly concave passenger demand in the strong market. Table 1 shows that the total number of passengers increases from 0.657 to 0.660 following a move from uniform pricing towards laissez-faire.

\section{The Welfare-optimal Congestion Charge}

\subsection{Welfare-optimal fares under price discrimination}

The congestion charge is chosen in the first stage of the game. Before investigating this charge, price discrimination with respect to fares and full prices is discussed from the viewpoint of welfare maximization. To write welfare as a function of fares $p_{s}$ and $p_{w}$, solve simultaneously the equilibrium conditions $\eta_{s}=B_{s}^{\prime}$ and $\eta_{w}=B_{w}^{\prime}$ for $q_{s}$ and $q_{w}$. Assume that this yields the unique demand of passengers in market $x$, denoted $D_{x}$, for $x \in\{s, w\}$. Welfare can then be rewritten as

$$
W=\int_{\eta_{s}}^{\infty} D_{s} d y+\int_{\eta_{w}}^{\infty} D_{w} d z+p_{s} D_{s}+p_{w} D_{w}
$$

where the lower limits of integration are the full prices, $\eta_{s}$ and $\eta_{w}$, to incorporate congestion costs. The welfare-optimal fares are obtained by maximizing $\mathscr{L}=W+\mu g$, where $\mu$ is a Lagrange multiplier. 
Assume that the welfare-optimal fares are determined by the first-order conditions

$$
\mathscr{L}_{s}=\left(p_{s}-\left(v_{s} D_{s}+v_{w} D_{w}\right) C^{\prime}\right) \frac{\partial D_{s}}{\partial p_{s}}-\mu=0
$$

and

$$
\mathscr{L}_{w}=\left(p_{w}-\left(v_{s} D_{s}+v_{w} D_{w}\right) C^{\prime}\right) \frac{\partial D_{w}}{\partial p_{w}}+\mu=0,
$$

where the subscripts indicate whether the partial derivatives are taken with respect to $p_{s}$ or $p_{w}$ (i.e. $\mathscr{L}_{x} \equiv \partial \mathscr{L} / \partial p_{x}$ for $x \in\{s, w\}$ ). To ensure the existence of a solution, assume that the bordered Hessian for this problem denoted by $\Psi$ is negative definit. More specifically,

$$
\Psi=\operatorname{det}\left(\begin{array}{ccc}
L_{s s} & L_{s w} & g_{s} \\
L_{s w} & L_{w w} & g_{w} \\
g_{s} & g_{w} & 0
\end{array}\right)=-\left[W_{w w}+W_{s w}+W_{s s}+W_{s w}\right]>0
$$

by assumption.

To understand the welfare effect of price discrimination, it is useful to have a closer look at the congestion costs. The total congestion costs are given by $\left(v_{s} q_{s}+v_{w} q_{w}\right) C$, while the marginal congestion costs are

$$
\frac{\partial}{\partial q_{x}}\left[\left(v_{s} q_{s}+v_{w} q_{w}\right) C\right]=v_{x} C+\Gamma
$$

for $x \in\{s, w\}$ with $\Gamma=\left(v_{s} q_{s}+v_{w} q_{w}\right) C^{\prime}$. This shows that marginal congestion costs are greater for passengers in the strong market than for passengers in the weak market, because $v_{s} \geq v_{w}$. Moreover, the first term (and only the first term) on the RHS of (15) is deducted from the marginal passenger benefits to reach the passenger demands in (1). This term is, hence, internalized by passengers, while the second term on the RHS of (15), $\Gamma$, is not internalized. $\Gamma$, therefore, determines the external part of the marginal congestion costs (e.g. Czerny and Zhang 2011). Denoting the welfare-optimal uniform fare by $p^{*}$ and welfare-optimal discriminating fares by $p_{s}^{d}$ and $p_{w}^{d}$, then there is a close relationship between $\Gamma$ and $p^{*}, p_{s}^{d}$ and $p_{w}^{d}$, as described in the following proposition:

Proposition 2 When $v_{s}>v_{w}$, (i) the uniform fare that is determined by the external part of the marginal congestion costs yields the first-best outcome (i.e. $p^{*}=\Gamma^{*}$ ), and (ii) the second-best discriminating fare in the strong 
market exceeds the first-best fare, while the second-best discriminating fare in the weak market is smaller than the first best-uniform fare (i.e. $p_{s}^{d}>p^{*}>$ $\left.p_{w}^{d}\right)$.

Proof See Appendix C.

It is well known that welfare losses can occur when the same good is sold at different prices (e.g. Robinson 1933 and Schmalensee 1981). In our context with delays and different values of time, full prices are different in the welfare maximum $\left(p^{*}+v_{s} C^{*} \geq p^{*}+v_{w} C^{*}\right)$. However, to reach the first-best solution, passengers still have to be priced equally by carriers in order to reach the welfare maximal allocation because the externality, $\Gamma$, is independent of the passenger type. The relationships between optimal fares under uniform pricing and price discrimination derived here thus extend the results obtained by Holmes (1989), who abstracted away from externalities and concentrated on profits (not welfare).

The infrastructure provider does not directly control fares but only controls the congestion charge. This is because fares are determined by carriers, who take the congestion charge as given in their second-stage Cournot rivalry. In what follows, the welfare-optimal congestion charge in the two-stage game is identified by backward induction.

\subsection{The second-best congestion charge}

Section 3 concentrated on a given congestion charge. In this section, stage one is analyzed, where the carriers' equilibrium behavior in stage two is anticipated correctly by the infrastructure provider and $\tau$ is chosen to maximize welfare. Welfare as a function of congestion charge $\tau$ can be obtained substituting fares $p_{x}$ by demands $P_{x}$ and equilibrium passenger numbers $q_{x}^{z}$ for $q_{x}(x \in\{s, w\}$ and $z \in\{u, d\})$ in welfare function (12).

Assume that the welfare-optimal choice of $\tau$ under price discrimination is determined by the first-order condition

$$
\frac{d W}{d \tau}=W_{s} \frac{d P_{s}}{d \tau}+W_{w} \frac{d P_{w}}{d \tau}=0
$$


To understand how the choice of $\tau$ is related to the welfare-optimal passenger fares, recall that $d P_{s} / d \tau=d P_{w} / d \tau$ in equilibrium, since $\phi$ is exogeneous. The first-order condition in (16) can, therefore, be rewritten as

$$
\left(W_{s}+W_{w}\right) \frac{d P_{s}}{d \tau}=0
$$

Since the second factor is nonzero, $W_{s}+W_{w}=0$ at the welfare maximum. Summing the equations in (13) and (14) also yields $W_{s}+W_{w}=0$, which shows that the welfare-optimal congestion charge leads to welfare-optimal fares $\left(\tau^{d} \rightarrow p_{s}^{d}\right.$ and $\left.p_{w}^{d}\right)$. Recall that Proposition 2 states that a uniform fare is required to yield the first-best welfare result. Since $\tau^{d}$ exactly reproduces fares $\left(p_{s}^{d}, p_{w}^{d}\right)$, it directly follows:

Proposition 3 When $v_{s}>v_{w}$ and carriers engage in price discrimination, the welfare-optimal congestion charge does not reach the first-best welfare result.

Since the first-best solution can only be reached under uniform pricing, this section concentrates on the second-best congestion charge that maximizes welfare under price discrimination $(\phi \geq 0)$.

Proposition 4 When $v_{s}>v_{w}$, the second-best congestion charge is given by

$$
\tau^{d}=\left(1-\frac{1}{n}\right) \Gamma^{d}+\frac{\left(q_{s}^{d}+q_{w}^{d}\right) B_{s}^{\prime \prime} B_{w}^{\prime \prime}+\left(q_{s}^{d} B_{s}^{\prime \prime}-q_{w}^{d} B_{w}^{\prime \prime}\right)\left(v_{s}-v_{w}\right) C^{\prime}}{n\left(B_{s}^{\prime \prime}+B_{w}^{\prime \prime}\right)} .
$$

Proof See Appendix D.

The optimal congestion charge in (18) is inversely related to market shares $(1 / n)$. For instance, when $n \rightarrow \infty$, the optimal congestion charge is equal to the external part of the marginal congestion costs, $\Gamma^{d}$. Moreover, since $n \rightarrow \infty$ implies an atomistic market structure, fares in the strong market and fares in the weak market are determined by the congestion charge and thus $p_{s}^{d}=p_{w}^{d}=\Gamma^{d}=\Gamma^{*}$, yielding the first-best result by Proposition 2. Two reasons can be identified for the relationship between the optimal congestion charge and market shares: first, carriers wholely or partly internalize marginal congestion costs if these are self-imposed (e.g. Brueckner 2002). ${ }^{7}$ Second, as pointed out by Pels and Verhoef (2004) and others,

\footnotetext{
${ }^{7}$ Begun with Brueckner (2002)'s seminal paper, the literature on airport congestion pricing includes, among others, Pels and Verhoef (2004), Zhang and Zhang (2006), Basso
} 
there is a "market power" effect: When elasticities are finite so that equilibrium fares increase in market concentration, the congestion charge should be small or even negative so as to induce low fares downstream, thereby correcting for carrier market power. While the elasticities of demand with respect to the full price is generally finite in reality, researchers (for example, Brueckner and van Dender 2008, Brueckner 2009 and Basso and Zhang 2010) have considered models with perfectly elastic demands so as to concentrate their analysis on pure congestion pricing. With perfectly elastic demands $\left(B_{x}^{\prime \prime} \rightarrow 0\right.$ for $\left.x \in\{s, w\}\right), \tau^{d}$ can reduce to the "pure congestion pricing part" $(1-1 / n) \Gamma^{d}$.

As indicated earlier, the existing literature on infrastructure congestion pricing mainly concentrates on a single type of passengers. To elaborate on the effect of passenger groups, suppose that $v_{s}=v_{w}$. In this instance, the second term on the RHS of (18) is clear-cut in sign and is negative, which implies the existence of an upper limit for the optimal congestion charge determined by $(1-1 / n) \Gamma^{d}$. By contrast, if $v_{s} \geq v_{w}$, then $\tau^{d}>(1-1 / n) \Gamma^{d}$ when

$$
v_{s}-v_{w}>-\frac{\left(q_{s}^{d}+q_{w}^{d}\right) B_{s}^{\prime \prime} B_{w}^{\prime \prime}}{\left(q_{s}^{d} B_{s}^{\prime \prime}-q_{w}^{d} B_{w}^{\prime \prime}\right) C^{\prime}}
$$

Thus, with the difference in time valuation, $(1-1 / n) \Gamma^{d}$ cannot be considered as an upper limit for the optimal congestion charge anymore. Since this result holds for all $\phi \geq 0$, it is true under uniform pricing as well as under price discrimination. This shows that the result obtained by Czerny and Zhang (2011), who concentrated on uniform fares and showed that an increase in $\tau$ can increase welfare by protecting high-time-value passengers from excessive congestion caused by low-time-value passengers, is also true when airlines price discriminate.

A natural upper limit for the optimal congestion charge is given by the fare in the strong market. This is because carrier profits are nonnegative in equilibrium, which implies $\tau^{d} \leq p_{s}^{d}$. On the other hand, rearranging the equilibrium condition in (4) for $x=w$ and $\lambda^{i}=0$ yields

$$
\tau^{d} \leq P_{w}^{d}+\frac{1}{n}\left[\left(B_{w}^{\prime \prime}-v_{w} C^{\prime}\right) q_{w}^{d}-v_{s} q_{s}^{d} C^{\prime}\right]<P_{w}^{d},
$$

and Zhang (2008) and Brueckner and van Dender (2008). See Daniel (1995) for earlier work on the internalization idea. 


\begin{tabular}{lrrrrrrrr}
\hline & $\tau$ & $q_{s}$ & $q_{w}$ & $q$ & $p_{s}$ & $p_{w}$ & $\eta_{s}$ & $\eta_{w}$ \\
\hline \hline Uniform pricing & 0.249 & 0.284 & 0.342 & 0.626 & 0.523 & 0.523 & 1.086 & 1.055 \\
Laissez-faire & 0.252 & 0.236 & 0.365 & 0.601 & 0.606 & 0.446 & 1.147 & 0.957 \\
\hline
\end{tabular}

Table 2: Outcomes at the subgame-perfect equilibrium when the demand in the strong market is concave. Parameters: $v_{s}=$ $18 / 20, v_{w}=17 / 20, n=3$.

which shows that the fare in the weak market is an upper limit for the optimal congestion charge in the laissez-faire scenario $\left(\phi \geq 0\right.$ and $\left.\lambda^{i}=0\right)$.

Summarizing the above discussion yields:

Proposition 5 When $v_{s}>v_{w}$ : (i) the optimal congestion charge can be higher than what would prevail when passengers were treated as of a single type, which is independent of price discrimination; and (ii) fares in the weak market are an upper limit for the welfare-optimal congestion charge.

\subsection{Specific functional forms}

Specific functional forms are used to further analyze the relationship between the welfare-optimal congestion charge and price discrimination. For instance, the specifications in (9) together with $C=q_{s}+q_{w}$ imply

$$
\frac{d \tau^{d}}{d \phi}=-\frac{v_{s}-v_{w}}{b_{s}+b_{w}} \leq 0
$$

for $b_{s}, b_{w}>0$. Thus, the first-best congestion charge under uniform pricing exceeds the second-best congestion charge under price discrimination when demands are linear. By contrast, under the alternative specification of benefits in the strong market in (11) (which lead to a concave demand in the strong market) and if $v_{s}=18 / 20, v_{w}=17 / 20$ and $n=3$, a move from uniform pricing towards price discriminations slightly increases the congestion charge $\tau^{d}$ from 0.249 to 0.252 (see Table 2). These observations lead to:

Proposition 6 When $v_{s}>v_{w}$, the effect of price discrimination on the welfare-optimal congestion charge can be positive or negative. 


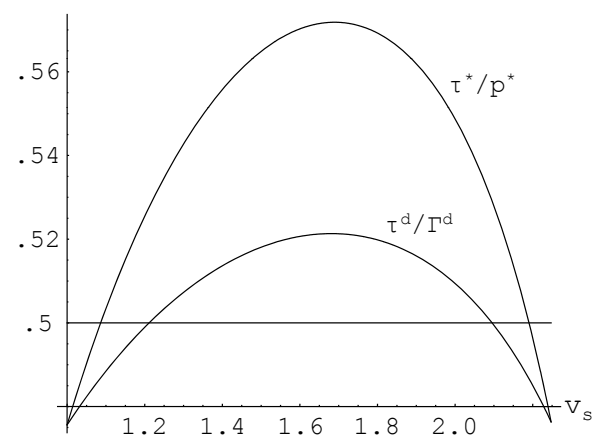

Figure 4: Ratios of the congestion charge and marginal external congestion costs. Parameters: $a=8 / 5, b_{w}=1 / 20, n=2, v_{w}=1$.

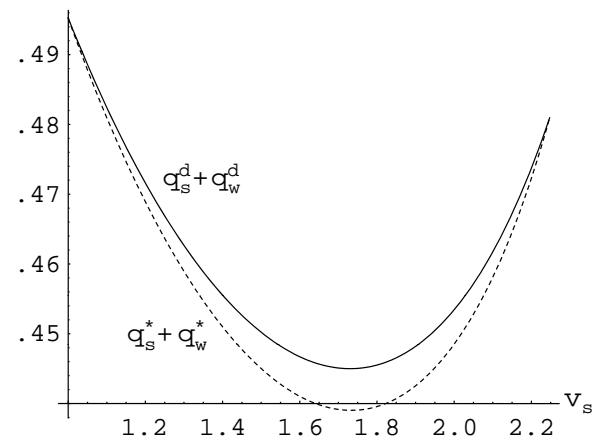

Figure 5: Total passenger numbers. Parameters: $a=8 / 5, b_{w}=$ $1 / 20, n=2, v_{w}=1$.

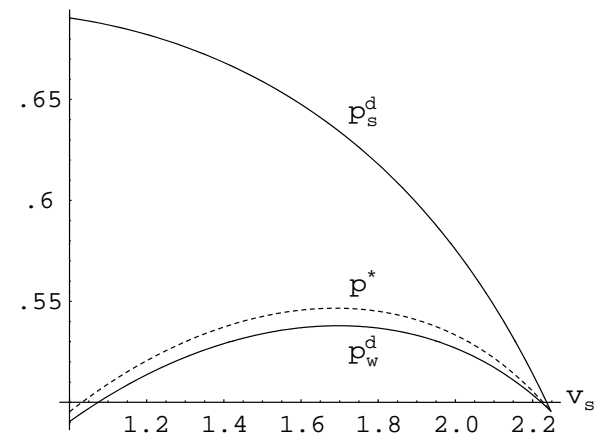

Figure 6: First-best fares and fares under laissez-faire. Parameters: $a=8 / 5, b_{w}=1 / 20, n=2, v_{w}=1$. 
The relationship between the first-best outcomes and the outcomes in the laissez-faire scenario is illustrated in the following. Suppose that the functional forms described in (9) and with $C=q_{s}+q_{w}$ hold for parameters $a=8 / 5, b_{w}=1 / 20, n=2$ and $v_{w}=1$. To understand the relationship between marginal external congestion costs $\Gamma$ and the congestion charge $\tau$, note that the optimal congestion charge in (18) implies $\tau^{*} / p^{*} \leq 1 / 2$ when $v_{s}=v_{w}$. By contrast, Figure 4 shows that parameter constellations exist, where $\tau^{*} / p^{*}>1 / 2$ or, respectively, $\tau^{d} / \Gamma^{d}>1 / 2$ when $v_{s}>v_{w}(=1)$. This shows that it can be useful to increase the congestion charge to a level that exceeds the external marginal congestion costs when passenger groups with different values of time exist, which can occur under both uniform pricing and under price discrimination. Such an increase in $\tau$ is to protect hightime-value passengers from excessive congestion caused by low-time-value passengers (Czerny and Zhang 2011).

Figure 5 displays total passenger numbers $q_{s}^{*}+q_{w}^{*}$ and $q_{s}^{d}+q_{w}^{d}$ as a function of $v_{s}$. This figure illustrates that price discrimination can lead to a greater total number of passengers. Recall that price discrimination reduces welfare relative to uniform pricing under the conditions considered in this paper. Figure 5 provides an example for a scenario where price discrimination reduces total welfare although total output is higher under price discrimination. This is consistent with the findings of Schmalensee (1981) and Varian (1985), who found that a necessary, but not sufficient, condition for price discrimination to increase social welfare is that output increases.

\section{Concluding Remarks}

We developed a tractable model with two groups of passengers, interdependent demands and congestion externalities, which we used to analyze the welfare effects of carrier price discrimination and infrastructure congestion pricing. We showed that price discrimination always leads to a loss of social welfare when, in the first stage, the congestion charge is chosen to maximize welfare and, in the second stage, carriers are in Cournot competition. The reason is that the first-best result can be implemented by the "right" choice of the congestion charge given that carriers charge uniform fares to passen- 
gers. By contrast, the first-best result cannot be reached given that carriers charge discriminating fares.

It is also shown that the effect of price discrimination on fares is difficult to predict when the infrastructure charge is considered as given. The effect of price discrimination on fares is clear-cut in the subgame-perfect equilibrium, however: the discriminating fare charged to passengers in the strong market always exceeds the first-best uniform fare, while the discriminating fare charged to passengers in the weak market is always smaller than the first-best uniform fare. Finally, with respect to the congestion charge for the case of multiple passenger types, it can be welfare-enhancing to increase the congestion charge to a level that exceeds the external marginal congestion costs, which is true under both uniform and discriminating fares.

\section{A The Proof of Lemma 1}

By Cramer's rule

$$
\begin{aligned}
\frac{d q_{s}}{d \tau} & =\frac{n}{\Xi_{i}} \operatorname{det}\left[\begin{array}{ccc}
1 & \left(\mathscr{L}_{\text {siwi }}^{i}+(n-1) \mathscr{L}_{\text {siwj }}^{i}\right) & g_{s i} \\
1 & \left(\mathscr{L}_{w i w i}^{i}+(n-1) \mathscr{L}_{\text {wiwj }}^{i}\right) & g_{w i} \\
0 & n g_{w i} & 0
\end{array}\right] \\
& =-\frac{n^{2}}{\Xi_{i}}\left(B_{s}^{\prime \prime}+B_{w}^{\prime \prime}\right)\left(B_{w}^{\prime \prime}+\left(v_{s}-v_{w}\right) C^{\prime}\right),
\end{aligned}
$$

which is ambiguous in sign only if $v_{s}>v_{w}$. On the other hand, both

$$
\frac{d q_{w}}{d \tau}=-\frac{n^{2}}{\Xi_{i}}\left(B_{s}^{\prime \prime}+B_{w}^{\prime \prime}\right)\left(B_{s}^{\prime \prime}-\left(v_{s}-v_{w}\right) C^{\prime}\right)
$$

and

$$
\frac{d\left(q_{s}+q_{w}\right)}{d \tau}=-\frac{n^{2}}{\Xi_{i}}\left(B_{s}^{\prime \prime}+B_{w}^{\prime \prime}\right)^{2}
$$

are negative in sign.

To derive the relationships between fares and the infrastructure charge, recall that $P_{s}=P_{w}+\phi$ and, thus, $d P_{s} / d \tau=d P_{w} / d \tau$. More specifically, 
the relationships in (23), (24) and (25) together with inverse demands in (1) yield

$$
\frac{d P_{x}}{d \tau}=-\frac{n^{2}}{\Xi_{i}}\left(B_{s}^{\prime \prime}+B_{w}^{\prime \prime}\right)\left[B_{s}^{\prime \prime} B_{w}^{\prime \prime}-\left(B_{s}^{\prime \prime} v_{w}+B_{w}^{\prime \prime} v_{s}\right) C^{\prime}\right]>0
$$

for $x \in\{s, w\}$.

\section{B The Proof of Proposition 1}

To derive the comparative-static results with respect to price discrimination $(\phi)$, it is helpful to denote

$$
\begin{aligned}
\zeta^{i}=q_{i s} B_{s}^{\prime \prime \prime} B_{w}^{\prime \prime}-q_{i w} B_{s}^{\prime \prime} B_{w}^{\prime \prime \prime}+\left(q_{i s} B_{s}^{\prime \prime \prime}+q_{i w} B_{w}^{\prime \prime \prime}\right)\left(v_{s}-v_{w}\right) C^{\prime} \\
-\lambda^{i}\left[B_{s}^{\prime \prime} B_{w}^{\prime \prime \prime}+B_{s}^{\prime \prime \prime} B_{w}^{\prime \prime}+\left(B_{s}^{\prime \prime \prime}-B_{w}^{\prime \prime \prime}\right)\left(v_{s}-v_{w}\right) C^{\prime}\right]
\end{aligned}
$$

for $i=1, \ldots, n$. Observe that $\zeta^{i}$ is zero when the (inverse) passenger demands with respect to the full price are linear (i.e. when $B_{x}^{\prime \prime \prime}=0$ for $x \in\{s, w\})$.

To establish part $i$, note that the relationship between the number of passengers in the strong market and price discrimination is determined by

$$
\frac{d q_{s}}{d \phi}=\frac{n}{\Xi_{i}}\left[\left(\mathscr{L}_{\text {wiwi }}^{i}+(n-1) \mathscr{L}_{\text {wiwj }}^{i}\right) g_{s i}-\left(\mathscr{L}_{\text {siwi }}^{i}+(n-1) \mathscr{L}_{\text {siwj }}^{i}\right) g_{w i}\right] \text {, }
$$

with

$$
\begin{gathered}
\mathscr{L}_{w i w i}^{i}=-q_{s i} v_{s} C^{\prime \prime}+2\left(B_{w}^{\prime \prime}-v_{w} C^{\prime}\right)+\left(B_{w}^{\prime \prime \prime}-v_{w} C^{\prime \prime}\right) q_{w i}+\lambda^{i}\left[B_{w}^{\prime \prime \prime}+\left(v_{s}-v_{w}\right) C^{\prime \prime}\right], \\
\mathscr{L}_{w i w j}^{i}=-q_{s i} v_{s} C^{\prime \prime}+B_{w}^{\prime \prime}-v_{w} C^{\prime}+\left(B_{w}^{\prime \prime \prime}-v_{w} C^{\prime \prime}\right) q_{w i}+\lambda^{i}\left[B_{w}^{\prime \prime \prime}+\left(v_{s}-v_{w}\right) C^{\prime \prime}\right] \\
\mathscr{L}_{s i w i}^{i}=-\left(v_{s}+v_{w}\right) C^{\prime}-\left(q_{s i} v_{s}+q_{w i} v_{w}\right) C^{\prime \prime}+\lambda^{i}\left(v_{s}-v_{w}\right) C^{\prime \prime}
\end{gathered}
$$

and

$$
\mathscr{L}_{\text {siwj }}^{i}=-v_{s} C^{\prime}-v_{s} C^{\prime \prime} q_{s i}-q_{w i} v_{w} C^{\prime \prime}+\lambda^{i}\left(v_{s}-v_{w}\right) C^{\prime \prime} .
$$


The relationship between the number of passengers in the weak market and price discrimination is determined by

$$
\frac{d q_{w}}{d \phi}=\frac{n}{\Xi_{i}}\left[\left(\mathscr{L}_{s i s i}^{i}+(n-1) \mathscr{L}_{s i s j}^{i}\right) g_{w i}-\left(\mathscr{L}_{w i s i}^{i}+(n-1) \mathscr{L}_{w i s j}^{i}\right) g_{s i}\right] .
$$

with

$\mathscr{L}_{s i s i}^{i}=2\left(B_{s}^{\prime \prime}-v_{s} C^{\prime}\right)+q_{i s} B_{s}^{\prime \prime \prime}-\left(q_{i s} v_{s}+q_{i w} v_{w}\right) C^{\prime \prime}+\lambda^{i}\left[-B_{s}^{\prime \prime \prime}+\left(v_{s}-v_{w}\right) C^{\prime \prime}\right]$,

$\mathscr{L}_{s i s j}^{i}=B_{s}^{\prime \prime}-v_{s} C^{\prime}+\left(B_{s}^{\prime \prime \prime}-v_{s} C^{\prime \prime}\right) q_{s i}-q_{w i} v_{w} C^{\prime \prime}+\lambda^{i}\left[-B_{s}^{\prime \prime \prime}+\left(v_{s}-v_{w}\right) C^{\prime \prime}\right]$

and

$$
\mathscr{L}_{w i s j}^{i}=-q_{s i} v_{s} C^{\prime \prime}-v_{w} C^{\prime}-q_{w i} v_{w} C^{\prime \prime}+\lambda^{i}\left(v_{s}-v_{w}\right) C^{\prime \prime} .
$$

The two relationships in (28) and (33) are ambiguous in sign. The ambiguous effects of price discrimination on the number of strong passengers and weak passengers is shown by numerical simulations in Section 3.2 (Figure 1).

The change in the total number of passengers depending on price discrimination is determined by

$$
\frac{d\left(q_{s}+q_{w}\right)}{d \phi}=\frac{n^{2}}{\Xi_{i}}\left[\left(B_{s}^{\prime \prime}+B_{w}^{\prime \prime}\right)\left(v_{s}-v_{w}\right) C^{\prime}+\zeta^{i}\right] .
$$

A positive (negative) relationship between the total number of passengers and price discrimination occurs when

$$
-\zeta^{i}<(>)\left(B_{s}^{\prime \prime}+B_{w}^{\prime \prime}\right)\left(v_{s}-v_{w}\right) C^{\prime}
$$

To establish part ii, recall that $\zeta^{i}=0$ when inverse demands are linear. If further $v_{s}-v_{w}=0$, the RHS of (37) reduces to 0 . On the other hand, if inverse demands are linear and $v_{s}-v_{w}>0$, the RHS of (37) is negative in sign.

To establish part iii, it is useful to distinguish between the two situations where price discrimination reduces or, respectively, increases the number of passengers in the weak market. If the number of passengers in the weak market is reduced and the total number of passengers is reduced, price discrimination increases fares in the weak and, hence, in the strong market. On the other hand, if the number of passengers in the weak market is increased by price discrimination, the number of passengers in the strong market must 
have been decreased because the total number of passengers is supposed to decrease by price discrimination. Thus, fares in the strong market must be greater under price discrimination in this situation as well.

\section{Proof of Proposition 2}

To establish part i, substitute $\left(v_{s} q_{s}+v_{w} q_{w}\right) C^{\prime}$ by $\Gamma$ in the first-order conditions in (13) and (14). Solving these conditions for fares yields

$$
p_{x}=\Gamma+\frac{\partial p_{x}}{\partial D_{x}} \mu
$$

for $x \in\{w, l\}$. Since $\phi \geq 0$ implies $p_{s} \geq p_{w}$, the RHSs of (39) imply $\mu \leq 0$, and since $\mu$ is the shadow price of price discrimination and negative in sign, price discrimination reduces welfare. Thus, welfare reaches its maximum for $\phi=0$ when carriers charge a uniform fare to all passengers (i.e. when $\phi=0$ ). Since $\phi=0$ leads to $\mu=0$, (39) implies that the (single) welfare-optimal fare, denoted by $p^{*}$, is given by $\Gamma^{*}$.

To establish part ii, Cramer's rule can be applied to obtain

$$
\frac{d p_{s}}{d \phi}=\frac{1}{\Psi} \operatorname{det}\left[\begin{array}{ccc}
0 & W_{s w} & -1 \\
0 & W_{w w} & 1 \\
-1 & 1 & 0
\end{array}\right]=-\frac{1}{\Psi}\left(W_{s w}+W_{w w}\right)>0
$$

and

$$
\frac{d p_{w}}{d \phi}=\frac{1}{\Psi}\left(W_{s s}+W_{s w}\right)<0 .
$$

This directly implies $p_{s}^{d}>p^{*}>p_{w}^{d}$ for $\phi>0$.

\section{Proof of Proposition 4}

The first-order condition in (16) can be rewritten as

$$
\frac{d W}{d \tau}=P_{s}^{d} \frac{\partial q_{s}^{d}}{\partial \tau}+P_{w}^{d} \frac{\partial q_{w}^{d}}{\partial \tau}-\left(q_{s}^{d} v_{s}+q_{w}^{d} v_{w}\right) C^{\prime} \cdot \frac{\partial\left(q_{s}^{d}+q_{w}^{d}\right)}{\partial \tau}=0
$$

Denote

$$
\alpha_{x}=\frac{\partial q_{x i}^{d} / \partial \tau}{\partial\left(q_{s}^{d}+q_{w}^{d}\right) / \partial \tau}
$$


with

$$
\alpha_{s}=\frac{B_{w}^{\prime \prime}+\left(v_{s}-v_{w}\right) C^{\prime}}{B_{s}^{\prime \prime}+B_{w}^{\prime \prime}} \text { and } \alpha_{w}=\frac{B_{s}^{\prime \prime}-\left(v_{s}-v_{w}\right) C^{\prime}}{B_{s}^{\prime \prime}+B_{w}^{\prime \prime}},
$$

where $\alpha_{s}$ is ambiguous in sign, $\alpha_{w}$ is positive in sign and $\alpha_{s}+\alpha_{w}=1$.

Rewriting the first-order condition in (42) yields

$$
\alpha_{s} p_{s}^{d}+\alpha_{w} p_{w}^{d}=\Gamma^{d}
$$

One can show that $\alpha_{s} g_{s i}^{i}+\alpha_{w} g_{w i}^{i}=0$. Multiplying the derivative in (4) by $\alpha_{x}$, summing up and manipulating, therefore, yields

$$
\alpha_{s} p_{s}^{d}+\alpha_{w} p_{w}^{d}=\tau^{d}-\alpha_{s}\left(q_{s i}^{d} \frac{\partial P_{s}}{\partial q_{s i}}+q_{w i}^{d} \frac{\partial P_{w}}{\partial q_{s i}}\right)-\alpha_{w}\left(q_{w i}^{d} \frac{\partial P_{w}}{\partial q_{w i}}+q_{s i}^{d} \frac{\partial P_{s}}{\partial q_{w i}}\right) .
$$

Deducting (45) from (46) and rearranging, finally, leads to the second-best congestion charge in (18), which holds for $\phi \geq 0$.

\section{References}

Basso, L. and Zhang, A. (2008). Sequential peak-load pricing in a vertical setting: The case of airports and airlines. Canadian Journal of Economics, 41: 1087-1119.

Brander, J. A. and Zhang, A. (1990). Market Conduct in the Airline Industry: An Empirical Investigation. RAND Journal of Economics, 21(4): $567-583$.

Brueckner, J. K. (2002). Airport congestion when carriers have market power. American Economic Review, 92(5): 1357-1375.

Brueckner, J. K. and van Dender, K. (2008). Atomistic congestion tolls at concentrated airports? Seeking a unified view in the internalization debate. Journal of Urban Economics, 64(2): 288-295.

Cheung, F. K. and Wang, X. (1997). The output effect under oligopolistic third-degree price discrimination. Australian Economic Papers, $35(68): 23-30$.

Czerny, A. I. and Zhang, A. (2011). Airport congestion pricing and passenger types. Transportation Research Part B: Methodological, 45(3):595604 . 
Dana, J. D. (1999). Using yield management to shift demand when the peak time is unknown. RAND Journal of Economics, 30(3): 456-474.

Dana, J. D. (1999a). Equilibrium price dispersion under demand uncertainty: the roles of costly capacity and market structure. RAND Journal of Economics, 30(4): 632-660.

Daniel, J. I. (1995). Congestion pricing and capacity of large hub airports: A bottleneck model with stochastic queues. Econometrica, 63(2): 327370.

Gravelle, H. and Reese, R. (2004). Microeconomics. Pearson Education Limited.

Hazledine, T. (2006). Price discrimination in Cournot-Nash oligopoly. Economics Letters, 93(3): 413-420.

Holmes, T. J. (1989). The effects of third-degree price discrimination in oligopoly. American Economic Review, 79(1): 244-250.

Mayer, C. and Sinai, T. (2003). Network effects, congestion externalities, and air traffic delays: Or why all delays are not evil. American Economic Review, 93(4): 1194-1215.

Morrison, S. A. (1987). The equity and efficiency of runway pricing. Journal of Public Economics, 34(1):45-60.

Morrison, S. A. and Winston, C. (1989). Enhancing the performance of the deregulated air transportation system. Brookings Papers on Economic Activity: Microeconomics, 61-112.

Morrison, S. A. and Winston, C. (2007). Another look at airport congestion pricing. American Economic Review, 97(5): 1970-1977.

Nocke, V., Peitz, M. and Rosar, Frank (2011). Advance-purchase discounts as a price discrimination device. Journal of Economic Theory, 146(1): $141-162$.

Oum, T. H., Zhang, A. and Zhang, Y. (1993). Inter-Firm Rivalry and Firm-Specific Price Elasticities in Deregulated Airline Markets. Journal of Transport Economics and Policy, 27(2): 171-192.

Pels, E., Nijkamp, P., and Rietveld, P. (2003). Access to and competition between airports: A case study for the San Francisco Bay area. Transportation Research Part A: Policy and Practice, 37(1):71-83. 
Pels, E. and Verhoef, E. T. (2004). The economics of airport congestion pricing. Journal of Urban Economics, 55(2): 257-277.

Robinson, J. (1933). The Economics of Imperfect Competition. Macmillan, London.

Schmalensee, R. (1981). Output and welfare implications of monopolistic third-degree price discrimination. American Economic Review, 71(1): 242-247.

Stavins, J. (2001). Price discrimination in the airline market: the effect of market concentration. Review of Economics and Statistics, 83(1): 200-202.

US Department of Transportation (1997). The Value of Saving Travel Time: Departmental Guidance for Conducting Economic Evaluations.

Varian, H. R. (1985). Price discrimination and social welfare. American Economic Review, 75(4): 870-875.

Zhang, A. and Zhang, Y. (1996). Stability of a Cournot-Nash equilibrium: the multiproduct case. Journal of Mathematical Economics, 26(4): 441-462.

Zhang, A. and Zhang, Y. (2006). Airport capacity and congestion when carriers have market power. Journal of Urban Economics, 60(2): 229247. 